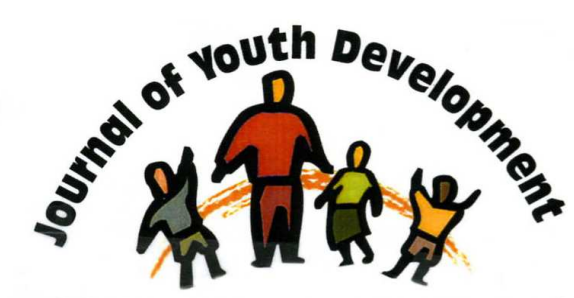

Bridging Research \& Practice

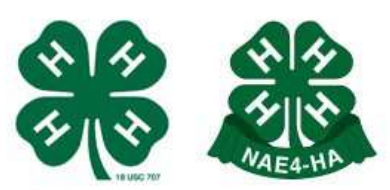

\title{
Components of Camp Experiences for Positive Youth Development
}

\author{
Karla A. Henderson \\ North Carolina State University \\ Raleigh, NC \\ karla henderson@ncsu.edu \\ M. Deborah Bialeschki \\ American Camp Association \\ Margery M. Scanlin \\ American Camp Association \\ Christopher Thurber \\ Phillips Exeter Academy \\ Leslie Schueler Whitaker \\ Philliber Research Associates \\ Paul E. Marsh \\ Indiana University
}

Department of Parks, Recreation and Tourism Management 


\title{
JOURNAL OF YOUTH DEVELOPMENT \\ bridging research and practice

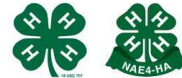

\section{Components of Camp Experiences for Positive Youth Development}

\author{
Karla A. Henderson \\ North Caroline State University \\ M. Deborah Bialeschki and Margery M. Scanlin \\ American Camp Association \\ Christopher Thurber \\ Phillips Exeter Academy \\ Leslie Schueler Whitaker \\ Philliber Research Associates \\ Paul E. Marsh \\ Indiana University
}

\begin{abstract}
Youth development specialists advocate that well designed, implemented, and staffed youth centered programs result in positive outcomes for young people. Youth organizations have provided opportunities for young people to participate in camping experiences for over a century. The purpose of this paper is to describe what program components were related to camp environments and positive youth development. We describe these program components related to positive youth development based on a large scale national study of ACA (American Camp Association) accredited camps that included independent, religiously affiliated, government, and not-for-profit organizations. Based on the responses given by camp directors, contact and leadership from trained staff and the supportive relationships they provided were essential elements of camp. Other aspects leading to positive youth development in camps were program mission and structure along with elements of accountability, assessment of outcomes, and opportunities for skill building.
\end{abstract}


Positive youth development encompasses a strength based conception of adolescence (Eccles \& Gootman, 2002; Lerner, Lerner, Almerigi, \& Theokas, 2005) Youth development specialists (e.g., Gambone, Klem, \& Connell, 2002; Leffert et al., 1998; Pittman, Irby, \& Ferber, 2000; Witt, 2002) have indicated that in addition to academic competence, youth need opportunities to grow toward physical, emotional, civic, and social competence. Further, youth development is dependent on supports from family, community, and other institutions such as organized recreation and camp programs (Witt \& Caldwell, 2005).

Youth development researchers such as Nicholson, Collins, and Hollmer (2004) and Baldwin, Caldwell, and Witt (2005) noted that evidence is mounting that well-designed, wellimplemented youth centered programs that consciously use a youth development model can have positive outcomes for young people. They suggest, however, that research should address the structures and settings that influence positive youth development.

Summer camps for young people have offered developmental opportunities in outdoor settings for over 100 years. The slogan of the American Camp Association (ACA) is "camp gives kids a world of good." Research studies (e.g., Bialeschki, Younger, Henderson, Ewing, \& Casey, 2002; Brannan, Arick, Fullerton, \& Harris, 2000; Chenery, 1991; Dworkin, 1999; Marsh, 1999) have documented the value of organized camp experiences facilitated by a variety of independent, religious, and youth agencies. A good deal of anecdotal evidence supports the "good" that camps provide. Since camps seem to be successful in promoting positive youth development, understanding how and why those positive effects occur is important.

The goal of the larger study from which this paper is based was to measure developmental change that occurred in young people as a result of their involvement in a summer camp experience that lasted at least one week. Understanding what happened to young people while at camp was important as was determining whether or not program components could be identified that facilitated positive outcomes. The purpose of this paper is to describe what program components were related to camp environments and positive youth development.

\section{Background}

Program components and structure relate to many aspects of youth development. Eccles and Gootman (2002) in Community Programs to Promote Youth Development identified several aspects that must be evident in youth programs if they are to provide positive youth development outcomes. This report stated that the components of youth programs should be based on:

- a developmental framework

- the commitment to accountability and assessment of outcomes

- trained staff

- physical and psychological safety

- appropriate structure

- supportive relationships

- opportunities to belong

- positive social norms

- opportunities to matter or make a difference

- opportunities for skill building

- integration of family, school, and community efforts 
Researchers (e.g., Spencer, Jordan, \& Sazama, 2004) have called for an examination beyond the usual description of social factors to include an analysis of how these factors work to produce outcomes. Camp experiences seem to have much to offer young people especially in terms of their structures and group living opportunities that provide supportive relationships, a sense of belonging, and skill building in a variety of ways.

Relationships, especially with staff, are central components to almost everything that happens in youth organizations. Many children lack access to supportive adults because of fractionalized families, erosion of neighborhood ties, and the time demands on family members. The supportive relationships established with young people are a key element leading to positive youth development, which has been found consistently in the youth development literature. For example, Spencer et al. (2004) examined important adults in youth's lives using relationalcultural theory as the guiding framework. Relational culture theory links the importance of growth-fostering connections and mutuality for psychological health in youth. The theory suggests that young people may in fact be moving toward relationships rather than autonomy as they mature. Spencer et al. used focus groups with ethnically and socioeconomically diverse groups of 7-18 year olds who described their desire for relationships and the value of respect, mutuality, and authenticity in their lives. The youth also described how these relationships took time and work and required the efforts of both, themselves and adults.

Child development literature has shown the positive relationship between staff development and quality programs for children (Huebner, Walker, \& McFarland, 2003). Huebner et al. noted that staff must understand positive youth development if they are to be successful in helping young people. Thus, they need to go through training to learn or reinforce this knowledge about development. Both a framework for articulating what positive youth development is and strategies for effective staff training are needed, especially when youth workers (e.g., camp staff) may not come with a common base of knowledge.

Staff training and professional development are critical components in seasonal, part-time, or fulltime jobs in any youth development organization. However, the Carnegie Corporation of New York (1992) noted "...youth-serving agencies...all report that adults who work with young people in their systems, whether serving on a paid or voluntary basis, are the most critical factor in whether a program succeeds, but do not receive adequate training, ongoing support and supervision, or public recognition" (p. 87). The bottom line is that an organization must invest resources and time in the program components of training and developing all staff. If the knowledge and skills necessary for positive youth development are reinforced with staff through training, the intentionality of the program goals and outcomes will likely be strengthened.

One approach to examining the relationship between program components at camps and positive youth development outcomes relates to the use of logic models. Baldwin et al. (2005) described an example of a logic model that stated program components such as trained and supportive staff have a direct relationship to program outcomes. The ultimate outcome in camps is for youth to grow into successful adulthood, which is typically defined as having met the distal outcomes of positive identity, positive values, social skills, and physical and thinking skills. The components that lead to these outcomes include deliberate programming and well trained staff.

In our ACA study we examined the youth development outcomes to ascertain if particular program components were more likely to lead to positive change. The broad research question 
we asked was, "If camp experiences lead to positive youth development outcomes, then what are the program components that can be associated with those outcomes?"

\section{Methods}

Data for the study of ACA accredited camps were collected in 2002 and 2003 from a national sample of over 5000 campers and their parents representing 92 camps from across the United States. The participating camps were selected from a stratified random sample of accredited day and resident camps in different parts of the country with varied sponsorships (i.e., agency, religiously affiliated, independent not for profit, and independent for profit). The study design included pre, post, and follow-up questionnaires given to campers and their parents, a pre and post observation checklist completed by staff, and questionnaires to camp directors regarding program components including characteristics, outcome goals, and operation details of their camps.

The instruments used in data collection were systematically developed and validated (see American Camp Association, 2005). Instruments were field tested to determine construct validity and reliability and pilot tested the summer before data collection began. The outcomes were measured by 52 questions using a 4-point Likert scale with 4=strongly agree to $1=$ strongly disagree. Ten constructs were aspects of four domains that reflected elements of positive youth development:

- Positive Identity (Positive Identity, Independence);

- Social Skills (Leadership, Making Friends, Social Anxiety, Peer Relationships);

- Positive Values and Spiritual Growth (Positive Values/Decision Making, Spirituality);

- Thinking and Physical Skills (Adventure/Exploration, Environmental Awareness).

The 92 camps studied included agency (e.g., 4-H, Girl Scouts, YMCA) (39\%), religiously affiliated (18\%), independent for profit (25\%), and independent not-for-profit (18\%) camps. Nearly $60 \%$ of the camps were one week camps. The sample of campers included $86 \%$ from resident camps and $14 \%$ from day camps. About one-third of the camps were from the East coast, one-third from the Midwest, and the final one-third from the South (10\%) and the West coast (14\%). Sixty-eight percent of the campers were female, $89 \%$ were white, and the average age was 11 years old, with 38\% under the age of 11 and $62 \%$ age 11 and older.

\section{Findings}

The first stage of data analysis focused on determining which outcomes indicated positive youth development as a result of camp experiences. A brief summary of those findings from the campers is a context for further examining the camp structures and staffing. The second aspect of the data analyses was to determine what program component differences related to outcome changes. The final stage was the description of the program components that were visible in the camps that were studied.

\section{Outcome Results}

From the pre to the post test, campers reported that they gained significantly in all domains and on six of the 10 constructs (for a summary of the results see American Camp Association, 2005). The greatest positive gains were in the areas of adventure/exploration skills followed by making friends, positive identity, independence, leadership, and spirituality. According to the camper data, no change occurred in feeling secure, environmental attitudes, and positive values. Parents of these same campers believed that gains were made in all the constructs from 
the pre to post test with the greatest gains in adventure/exploration skills, making friends, independence, and peer relationships. Staff observations also confirmed that positive change occurred for the four domains of positive identity, social skills, positive values and spirituality, and physical and thinking skills.

The camper characteristics associated with changes are important to mention. Campers who came to camp with lower pre-test scores (i.e., those children with lower skill levels or levels of social functioning) showed more positive change than those children who came with higher scores. Conversely, campers who came to camp with high pre-test scores showed more negative change than other youth. Most of the overall changes were small. Clearly, when children arrived at camp with high functioning levels the room for change was limited. Older children (i.e., over the age of 11 years) showed more positive change in all of the outcome areas except environment and positive values. Data from the parents' pre and post tests indicated that boys seemed to show more change after camp than girls in independence and positive values. Staff observations showed that boys had more positive change than girls related to social skills while at camp.

\section{Program Component Differences}

Knowing that positive changes occurred in campers was important to discover, but these results did not tell why the changes occurred. To the extent that youth development can be enhanced, the programmatic elements associated with change must be uncovered. In the second stage of data analyses, the program components related to camp structures were examined to ascertain whether any statistically significant differences existed among camps relative to the level of change self-reported by campers. This included:

- session length,

- sponsorship,

- day or resident structure,

- camper fees,

- budget size,

- staff and training (i.e., experience of the director, staff turnover),

- $\quad$ supportive relationships (i.e., staff to camper ratio), and

- developmental frameworks (i.e., targeted goals or outcomes)

Although contrary to what we hypothesized, no statistically significant differences across all camps were found related to youth development frameworks, camp formats, trained staff, and supportive relationships (American Camp Association, 2005). For example, day camps were no more or less likely to produce positive outcomes than resident camps. The amount of staff training did not result in statistically significant differences. Therefore, the next step in the analysis process was to examine how the camp components seemed to be working collectively to contribute to youth development.

People closely associated with camps may be surprised that no structural elements related directly to outcomes, but noting that all camps in this study had met or exceeded accreditation standards is important. Perhaps structural elements and staff training make little difference when camps are held to high standards for their programs and operations as required through ACA Accreditation. No differences may suggest that multiple camp formats contribute similarly to growth outcomes in youth. Nevertheless, the value of understanding more about camp experiences may lie in describing in more detail what camps do that seems to contribute to successful youth development. 


\section{Program Component Descriptions}

In the remainder of this paper, we address information about program components from the camps studied relative to research findings about positive environments for youth development. We describe data obtained from 92 camp directors involved in this study related to four of the components identified by Eccles and Gootman (2002) for positive youth development:

- developmental framework,

- appropriate structure,

- trained staff, and

- $\quad$ supportive relationships.

Developmental framework. Almost $70 \%$ of the camp directors said they had a strategic plan in place for their camp with $16 \%$ saying that they were in the process of developing one. Ninety percent of the camp directors said their camps had a mission statement and $60 \%$ said they had written outcome statements. Over $45 \%$ of the directors believed they were highly effective in carrying out their mission statement. About $64 \%$ of the camp directors said positive identity was one of their top two outcome goals while $38 \%$ chose social skills and $26 \%$ chose personal values as outcome goals.

The major ways directors said they addressed their mission and their top outcome goals were:

- focus on the quality of staff and camper interaction (75\%),

- provide staff training specific to the outcome (49\%),

- give camper roles in decision-making (33\%),

- offer specific types of activities (31\%),

- provide progression in camp activities (26\%),

- consider staff to camper ratios (25\%),

- teach specific skills to campers to address the desired outcome (24\%),

- design program structure to address the outcomes (24\%),

- $\quad$ offer religious or spiritual activities (i.e., primarily indicated for those camps that were religiously-affiliated) (20\%), and

- $\quad$ purposely grouping campers (12\%).

Appropriate structure. Over half the camps had session lengths of only one week (Note: In this study, we set 5 days per session as the minimum amount of time necessary to be included in the research). The range included 5 days to 53 days with an average across the camps of 14 days with only $10 \%$ of the children surveyed going to camp five or more weeks. As noted previously, the length of the session was not statistically related to positive growth in campers.

Over $80 \%$ of the camps indicated that they were a "general" camp meaning they had a variety of programs compared to $18 \%$ who considered themselves a specialty camp (e.g., arts, wilderness trips, horseback riding). The median number of identified program activities offered in each camp was 15 with one-third of the camps offering twenty or more different program activities. Almost half of the camps were coeducational with one-third girls only and $14 \%$ boys only.

The number of campers served at any one time at a camp averaged 190 with the median of 144 campers. The numbers served in each camping session ranged from 60-1375 campers. The income ranges of the children's families varied greatly with about $16 \%$ of the campers coming from families with less than $\$ 20,000$ per year and $15 \%$ from families that were 
estimated to make over $\$ 200,000$ a year. A quarter of the families were projected to have an annual household income of $\$ 20-50,000$ with a third in the income range of $\$ 50-100,000$.

Half of the camps had a summer operating budget of over a quarter of a million dollars with an average of $\$ 375,430$ and the range from under $\$ 10,000$ to over two million dollars a year. Almost three-fourths of the directors said their budget had increased from the previous year while $22 \%$ said it had remained the same. Almost $70 \%$ said the trend was toward charging higher fees. The cost of camp was less than $\$ 200$ per week for about $20 \%$ of the campers, but almost $50 \%$ of the camps charged $\$ 300$ or more per week. The average cost per camper per session ranged from free to $\$ 7000$ depending on the type of camp and length of session.

Over half of the camp directors indicated that they were constantly seeking to implement new ideas in camp with most of the remaining directors indicating that they made regular improvements from year to year in their program operations. Eighty percent of the directors said that campers had some input into planning their camp activities. Two-thirds of the camps indicated that campers had some input in the delivery of programs with $23 \%$ indicating that campers had considerable involvement. All camp directors indicated that campers had at least some involvement in evaluating the program with $60 \%$ indicating that they had considerable involvement. The camps were split with almost $50 \%$ indicating that the camper chose most of his or her daily activities and a little over $50 \%$ indicating that staff members made most of the choices for daily camper activities.

Trained staff. Over three-fourths of the camp directors were full-time, year-round employees with only $9 \%$ who were seasonal (i.e., summer employees). The majority of the camp directors were 31 years or older (84\%). They were almost split evenly in terms of gender with $53 \%$ female. Over $90 \%$ of the directors held at least a bachelors degree with $38 \%$ holding a Masters degree. Camp directors indicated that on average they spent about 47 hours a year in training or participating in continuing education and professional development opportunities that related directly to their work in camping.

Camp directors said they had spent an average of over five years as campers themselves. The directors said they had been a staff member at a camp (e.g., counselor, activity leader, assistant director) for eight years. About one-third of the directors had experience as a director at another camp prior to the one where they were now employed and another one-third had been at their present camp for more than 10 years. The average time as a director at the present camp was 9.4 years with a range from $0-36$ years.

The majority of staff members working at camp were between the ages of 18-24 years. The average number of staff in camp that were under 18 years old was 4.5 but $53 \%$ of the camp directors said they had no staff under 18 years. The average number of staff aged 24 years and older was 6 per camp or 14\%. Directors indicated that on average they had 21 staff between the ages of $18-20(48 \%)$ and $12(27 \%)$ between the ages of $21-23$ years. About a quarter of the staff at camp held a bachelors degree. Camp directors indicated that on average $50 \%$ of their staff returned each year. They indicated that about $10 \%$ of their staff were international staff (i.e., were in camp on a J-1 visa).

The average time spent in instruction for camp staff prior to camp beginning (i.e. pre-camp training) was 60 hours. Directors reported that about 15 hours were spent discussing and providing instruction about the camp goals with the median being about 7 hours and a range of 
0-80 hours. About one third of the directors felt that the amount of time spent in staff training was not enough with $58 \%$ believing the time was adequate.

Supportive relationships. The average camp in this stratified random sample had 42 staff but this number ranged from 2 to 168 staff members with a median number of 36 individuals. The camp directors indicated that $65-75 \%$ of the time their staff was participating with their assigned group of campers. Over $50 \%$ of the camps had counselors who slept in the same cabin or room as the campers with another $20 \%$ sleeping in the same building as the campers. Cabin size varied but the average number of staff per cabin was two.

Over half the camps indicated that the ratio of staff to campers including all staff employed was about 1:3. The staff to camper ratio of only staff assigned to campers in units or living groups (i.e., counselors) was about 1:4. According to ACA standards, the ratio should vary depending on the age and abilities of the campers. Day camps, which usually focus on younger children, had an average of 16 campers in a group lead by 2-3 counselors in that group.

\section{Discussion}

These descriptive details about program components provide a foundation for examining positive youth development. The statistical analyses did not show differences in components such as amount of training or camp to staff ratios, so it appeared that camps may have aspects in common that contributed to youth development. An analysis of these data compared to evidence from the youth development literature gives additional insight how program components contribute to youth development.

Peterson (2004) concluded from existing program evaluation literature that the following "truisms" exist and are relevant to explaining why camp experiences seem to be venues for positive youth development. He noted that more contact is better, clear structures are needed, sophisticated programs are better if they are developmentally appropriate and impart skills and competencies, and programs work best when they are well planned and implemented. In addition, as was noted earlier in this paper, programs that have the most potential to influence youth development are based on a developmental framework, use trained staff, provide appropriate structures, and encourage supportive relationships (Eccles \& Gootman, 2002).

This national ACA outcomes study showed positive growth based on the pre and post test results from both, campers and parents. Therefore, elements of camp components seemed to be working, even though no statistically significant differences were found. Based on the responses given by camp directors, contact and leadership from trained staff and the supportive relationships they provided were essential elements of camp. Other aspects leading to positive youth development in camps were program mission and structure along with elements of accountability, assessment of outcomes, and opportunities for skill building. These accredited camps collectively seemed to have program components that were working in terms of measuring youth development outcomes.

The human relations dimensions of camp in terms of trained staff and supportive relationships were evident. First, most of the camp directors were employed year round and held at least a bachelors degree. These directors had extensive experience themselves as campers and as staff members prior to assuming their camp leadership role. Thus, they brought a combination of experience and education to their positions. More importantly, they indicated that being a camp director meant a commitment to continuing education to address the changing world in 
which young people live. These directors brought a commitment and an expertise to camp that emphasized the importance of youth development knowledge, strategies, and outcomes.

Second, and just as important as the camp director, was the contribution staff made to enhancing youth development through their training and supportive relationships. These staff members were primarily young adults who had a desire to influence young people's lives or they would not have been at camp. About $50 \%$ of the staff returned each year, which enabled the potential for greater intensity of on-going contact and relationship continuity. The diversity of staff backgrounds as well as the international status of some staff added a perspective that could influence the positive values campers learned in camp.

In addition, campers spent most of their time at camp with their living group and especially time in contact with their counselors. The staff to camper ratios can vary by age according to the ACA Accreditation Standards, but overall one adult to four young people as an average ratio is admirable for any youth organization or program. Even if staff did not come with indepth knowledge of youth development, they were given extensive pre-camp training once they arrived at camp (e.g., directors said they spent the equivalent of one full day talking about the camp's mission, goals, and the growth they hoped campers would experience at camp).

Most camp directors were serious about the value of establishing a developmental framework that included strategic planning and the embodiment of mission statements that focused on youth development. Many camp directors seemed to recognize that the process of planning and implementing goals was a challenging proposition but one that they were committed to improving.

Camp directors articulated that positive identity, social skills, and personal values were top priorities for them regardless of their camp structure. Since these areas represented aspects of positive growth in campers, camps appeared to be successful in their deliberate and intentional programming. Camp directors also described the ways that they tried to address these goals through such activities as staff training, encouraging quality staff and camper interactions, and giving campers decision-making opportunities. Almost all the camp directors indicated that they were regularly trying to make improvements in their camp operations.

Camps were structured to give young people opportunities to make choices about the planning of their activities within cabin/living groups or for all camp activities. Many camp directors said they allowed youth to be involved in delivering the camp programs and in evaluating the camp's success. Staff and campers worked closely together in most cases when determining how a camper chose his or her daily activities. A great deal of variation existed across camps, but clearly most camp staff were attuned to balancing the camp's program outcome goals with the needs and interests of individual campers.

As a consequence, these camp experiences implemented with a well trained staff seemed successful in translating the camp goals into positive outcomes. The logic model was supported in showing a direct relationship between program components and distal outcomes (Baldwin et al., 2005).

\section{Conclusion}

This discussion does not suggest that all camps are perfect in their delivery of services to young people. The camps in this study were all accredited by ACA and the camp administrators had 
made a commitment to meeting the standards of best practices that encouraged safe positive environments for campers. We concluded on the basis of this study that camp components are associated with positive youth development. Although more is yet to be learned, camp is one context for "enriching lives and building tomorrows" for youth.

\section{References}

American Camp Association (2005). The youth development outcomes of the camp experience (YDOCE) study. Martinsville, IN: American Camp Association.

Baldwin, C., Caldwell, L, \& Witt, P. (2005). Deliberate programming with logic models: From theory to outcomes. In $L$ Caldwell and P. Witt (Eds.). Youth development and recreation services (pp. 219-240). State College, PA: Venture Publishing.

Bialeschki, M.D., Younger, T., Henderson, K., Ewing, D., \& Casey II, M. (2002). Happy but sad. Camping Magazine, 75(1), 38-41.

Brannan, S., Arick, J., Fullerton, A., \& Harris, J. (2000). Inclusive outdoor programs benefit youth. Camping Magazine, 73(1), 26-29.

Carnegie Corporation of New York. (1992). A matter of time: Risk and opportunity in the nonschool hours. San Francisco: Jossey-Bass.

Chenery, M.F. (1991). I am somebody: The messages and methods of organized camping for youth development. Martinsville, IN: American Camping Association.

Dworkin, B.S. (1999). Campers speak: New England youth share ideas on societal issues. Camping Magazine, 72(5), 30-34.

Eccles, J., \& Gootman, J.A. (Eds). (2002). Community programs to promote youth development. Washington, DC: National Academy Press.

Gambone, M.A., Klem, A.M., \& Connell, J.P. (2002). Finding out what matters for youth: Testing key links in a community action framework for youth development. Philadelphia: Youth Development Strategies, Inc. and Institute for Research and Reform in Education (http://www.ydsi.org/YDSI/pdf/Whatmatters.pdf)

Huebner, A.J., Walker, J.A., \& McFarland, M. (2003). Staff development for the youth development professional: A critical framework for understanding the work. Youth \& Society, 35(2), 204-225.

Leffert, N., Benson, P.L., Scales, P.C., Sharma, A.R., Drake, D.R., \& Blyth, D.A. (1998). Developmental assets: Measurement and prediction of risk behaviors among adolescents. Applied Developmental Science, 2(4), 209-230.

Lerner, R.M., Lerner, J.V., \& Almerigi, J., \& Theokas, C. (2005). Positive youth development: A view of the issues. Journal of Early Adolescence, 25(1), 10-16. 
Marsh, P. (1999). Does camp enhance self-esteem? Camping Magazine, 72(6), 36-40.

Nicholson, H.J., Collins, C., \& Holmer, H. (2004). "Youth as people" The protective aspects of youth development in after-school settings. The Annals of the American Academy of Political and Social Science, 591, 55-71.

Pittman, K., Irby, M., \& Ferber, T. (2000) Unfinished business: Further reflections on a decade of promoting youth investment. Takoma, MD: The Forum for Youth Development. (http://www.forumforyouthinvestment.org/unfinishedbusiness.pdf)

Spencer, R., Jordan, J.V., \& Sazama, J. (2004). "Growth-producing relationships between youth and adults: A focus group study." Families in Society, 85(3), 354-62.

Witt, P.A. (2002). Youth development: Going to the next level. Parks \& Recreation, 373), 5259.

Witt, P.A., \& Caldwell, L.L. (Eds.). (2005). Recreation and youth development. State College, PA: Venture Publishing.

(C) Copyright of Journal of Youth Development $~$ Bridging Research and Practice. Content may not be copied or emailed to multiple sites or posted to a listserv without copyright holder's express written permission. Contact Editor at: patricia.dawson@oregonstate.edu for details. However, users may print, download or email articles for individual use.

ISSN 2325-4009 (Print); ISSN 2325-4017 (Online) 